Published in final edited form as:

Int J Technol Assess Health Care. 2019 June 17; 35(4): 317-326. doi:10.1017/S0266462319000448.

\title{
Cost-effectiveness evaluations of psychological therapies for schizophrenia and bipolar disorder: a systematic review
}

\author{
Gemma Elizabeth Shields, BSc, MPH ${ }^{1}$, Deborah Buck, BA, $\mathrm{PhD}^{2}$, Jamie Elvidge, BA, $\mathrm{MSc}^{3}$, \\ Karen Petra Hayhurst, BSc, MSc, PhD $^{4}$, Linda Mary Davies, BA, MSc ${ }^{1}$ \\ ${ }^{1}$ Centre for Health Economics, Division of Population Health, University of Manchester \\ ${ }^{2}$ Personal and Social Services Research Unit, University of Manchester \\ ${ }^{3}$ National Institute for Health and Care Excellence, UK \\ ${ }^{4}$ Division of Psychology and Mental Health, University of Manchester, Manchester, M13 9PL, UK
}

\section{Abstract}

Objectives-This review aims to assess the cost-effectiveness of psychological interventions for schizophrenia/bipolar disorder (BD), to determine the robustness of current evidence and identify gaps in the available evidence.

Methods-Electronic searches (PsycINFO, MEDLINE, Embase) identified economic evaluations relating incremental cost to outcomes in the form of an Incremental Cost-Effectiveness Ratio (ICER) published in English since 2000. Searches were concluded in November 2018. Inclusion criteria were: adults with schizophrenia/BD; any psychological/psychosocial intervention (e.g. psychological therapy and integrated/collaborative care); probability of costeffectiveness at explicitly-defined thresholds reported. Comparators could be routine practice, no intervention, or alternative psychological therapies. Screening, data extraction, and critical appraisal were performed using pre-specified criteria and forms. Results were summarised qualitatively. The protocol was registered on the PROSPERO database (CRD42017056579).

Results-Of 3,864 studies identified, 12 met the criteria for data extraction. All were integrated clinical and economic randomised controlled trials. The most common intervention was cognitive behavioural therapy (CBT, 6/12 studies). The most common measure of health benefit was the quality-adjusted life-year (QALY) (6/12). Follow-up ranged from 6-months to 5-years. Interventions were found to be cost-effective in most studies (9/12): the probability of costeffectiveness ranged from $35-99.5 \%$. All studies had limitations and demonstrated uncertainty (particularly related to incremental costs).

Conclusions-Most studies concluded psychological interventions for schizophrenia/BD are cost-effective, including CBT, though there was notable uncertainty. Heterogeneity across studies

Corresponding address: Gemma E Shields, Centre for Health Economics, Division of Population Health, Health Services Research and Primary Care, Faculty of Biology, Medicine and Health University of Manchester, Manchester, M13 9PL,

gemma.shields@manchester.ac.uk, 07851357983.

Conflict of interest

The authors declare that they have no conflicts of interests. 
makes it difficult to reach strong conclusions. There is a particular need for more evidence in the population with $\mathrm{BD}$ and for longer-term evidence across both populations.

\section{Keywords}

schizophrenia; bipolar disorder; cost-effectiveness; cost-utility; economic evaluation

\section{Background}

Schizophrenia and bipolar disorder (BD) are among the top 20 causes of disability in the world, with an estimated 15.2 million years lived with disability (YLD) due to schizophrenia and 9.9 million YLD due to BD globally (2013 estimates) (1). The rate of all-cause mortality in schizophrenia and BD, over 15-year follow-up, is 2.08 and 1.77 times greater than the general population, respectively (2). Additionally, the premature mortality gap between individuals with schizophrenia and $\mathrm{BD}$, and the general population is growing (2). The majority of premature deaths are linked to physical illness, such as cardiovascular and metabolic disease (2-8). Review evidence points to a link between premature mortality and morbidity and long-lasting negative health behaviours (7). A wide range of other factors also impact on quality of life, including cognitive impairment, discrimination, stigma, social exclusion, and reduced opportunities for employment and education $(7,9,18,19,10-17)$. The impact on caregivers quality of life and time is also substantial (7).

As well as the humanistic burden, there is a large economic burden associated with schizophrenia and BD. Review evidence points to annual costs attributed to schizophrenia of between US\$94 million and US\$102 billion for different countries across the world (20). At least half $(50-85 \%)$ of these were indirect costs, such as productivity loss (e.g. absenteeism from work) or informal care (20). Total costs for people with schizophrenia and BD are estimated to reach $£ 14.7$ billion by 2026 , with $57 \%$ of these associated with lost earnings (21).

Typically, the first-line therapeutic option for schizophrenia or BD is pharmacological (e.g. antipsychotic medication and/or mood stabilisers). However, some individuals do not adhere to, or actively decline medication for a variety of reasons; and symptoms may be unresponsive to medication, or require further support (22). Psychological therapies, plus usual care (typically pharmacological treatments), can improve symptoms, and increase quality of life and functioning in people with schizophrenia and BD (23-26). Guidelines suggest that psychological therapies should be part of management strategies that are tailored to individual needs $(27,28)$.

People with schizophrenia and BD comprise the majority of the population with severe mental illness; $94 \%$ of severe mental health service users in the UK have a diagnosis of either schizophrenia or BD (29). Available literature highlights the economic and patient burden of schizophrenia and $\mathrm{BD}$, demonstrating the need for effective treatment in this patient group. Constraints on health and social care funding require that existing resources are allocated efficiently; economic evaluation provides a useful tool to support decision making for these patient groups. 
Most systematic reviews of the cost-effectiveness of treatments for psychosis have focused on pharmacological therapies. Three previous reviews which included psychological therapies were identified for schizophrenia or BD (30-32). Amos et al. (2012) focused on early intervention (EI) for psychosis (30). Desmedt et al. (2016) evaluated the costeffectiveness of integrated care models for people with chronic diseases, which included six studies on schizophrenia (31). Finally, Pari et al. (2014) focused on management strategies (including pharmacological management) for BD (32). While these reviews are valuable, they contain little recent evidence and are somewhat limited in scope, either by intervention or population group. Therefore, a more up-to-date literature search and comprehensive synthesis of the evidence is required to support evidence-based practice and research in the field.

The aim of this review was to determine the robustness of the current evidence base for economic evaluations of psychological interventions for schizophrenia or $\mathrm{BD}$, and to identify any gaps in this evidence base.

\section{Methods}

The review protocol was published on the online PROSPERO international register of systematic reviews (CRD42017056579) (33).

\section{Search strategy}

Searches were initially performed in August 2015 and were updated in January 2017 and November 2018. Searches were restricted to publications from year 2000 onwards (to maximise relevance to current practice) in English language on the OVID Medline, EMBASE and PsychINFO databases. The NHS EED database was searched in the initial search; later searches excluded this database since new papers were not added after 2015. Search terms included terms specific to economic evaluation, the population of interest, and psychological therapy. Strategies and terms varied according to the database design. Freetext and standardised (MESH) subject terms were used. Strategies were pilot tested to ensure all studies already known to the authors were retrieved. The full search strategies are provided in the supplementary material (supplementary material, Table 1).

\section{Selection of studies}

Inclusion criteria are outlined in Table 1. Studies not meeting these criteria were excluded during the screening process.

Independent screening was undertaken at two stages (firstly of abstracts and titles, then of full papers) by four reviewers (GES, DB, KPH, JE). A fifth reviewer was used to resolve disagreements (LMD). The primary reason for exclusion was recorded at both stages.

\section{Data extraction and quality appraisal}

The NHS EED quality checklist for data extraction and critical appraisal was adapted to develop a predefined data extraction form and the CHEERS checklist was used to support critical appraisal $(34,35)$. Data extraction and quality assessment included information on 
study methodology, results, limitations, evidence gaps and risk of bias. Data extraction was completed by one reviewer (DB papers published until 2016; LMD papers published from 2016 onwards) with $20 \%$ of data extraction checked by a second reviewer (GES).

Review findings are presented via narrative synthesis. As expected, and typical of economic evaluations, included studies and interventions were highly heterogeneous, limiting the usefulness of any quantitative synthesis (e.g. meta-analysis).

Cost values were converted into 2017 US dollars, using the price index for each country and the purchasing power parity conversion factor, to facilitate comparison between studies set in different countries $(36,37)$.

\section{Results}

In total 4,412 articles were identified through database searches; 3,864 remained after excluding duplicates. Primary screening of abstracts and titles reduced this to 232 papers for full text review. Twelve papers, specific to schizophrenia or BD, were identified and included in the review.

An overview of the key study characteristics is provided in Table 2 .

\section{Critical appraisal}

An overview of the quality of reporting (using the CHEERS checklist) of the economic evaluations is provided in the supplementary material (supplementary material, Table 2).

Population-According to trial recruitment criteria, the majority of study populations were predominantly made up of participants with schizophrenia $(38,40-48)$. Two studies focused on participants with BD $(39,49)$. Study participants were predominantly male and between 23-46 years old (Table 2). Note that this review included studies considering a population with an author reported diagnosis of schizophrenia or BD, exact diagnosis criteria could vary across studies.

There was inconsistency in how duration of illness was defined. Three studies did report duration of illness: Barton et al. (2009) reported a mean of 4.8 years, van der Gaag et al. (2011) 10.14 to 11.02 years, and Priebe et al. (2016) a median of 11 years (range 7 to 18) $(40,43,47)$. Patel et al. (2010) reported that over a half of patients had been in contact with psychiatric services for at least 10 years (42). McCrone et al. (2010) reported the proportion of patients with a first episode of psychosis (86\% in the intervention group versus $71 \%$ in the control group) (41). Two studies reported the duration of untreated illness: Karow et al. (2012) reported means of 167 and 182 weeks in the intervention and control arms, respectively, and Rosenheck et al. (2016) a median of 74 weeks $(45,48)$. One study reported the age of onset (22 years) (44), while another focused on the mean number of previous hospitalisations (6.3 in the intervention arm, 5.1 in the control arm) (39). Camacho et al. (2017) reported that over a half of participants had 20 or more previous bipolar episodes (49). In two studies duration of illness was not reported at all $(38,46)$. These differences in quantifying duration of illness demonstrate the challenges in comparing study populations 
and drawing conclusions related to subgroups or specific populations. The observed variation in study populations (some of which is unclear due to differences in reporting) means that we are unable to differentiate between subgroups. Therefore, we considered the 12 studies as a whole.

Intervention and comparator-The most common intervention was CBT (6/12 studies) (38-43). The inclusion of CBT is clearly associated with publication date; the 6 oldest studies evaluate CBT as an intervention whereas the 6 more recent studies consider alternative psychological interventions. Four studies considered interventions focusing on multidisciplinary provision of care $(41,45,46,48)$. Three other intervention types were identified; Crawford et al. (2012) evaluated art therapy, Priebe et al. (2016) evaluated body psychotherapy (which uses movement and the body as a form of treatment) and Camacho et al. (2017) evaluated group psychoeducation which aims to enhance people's understanding of their condition $(44,47,49)$. "Standard care" was the most common comparator $(9 / 12)$ $(38,39,41-46,48)$. Standard care definitions varied across studies, but common themes included usual access to secondary mental health services and pharmacological treatment. The exact components of standard care (e.g. specific medications and doses) were not typically reported however, these are likely to be reported in the trial publications. One study did not describe standard care at all (42). This variation reduces the generalisability of each study.

Measure of health benefit-Six of the included articles presented a CUA $(40,44,45,47-$ 49), typically using the generic EQ-5D questionnaire to derive utilities and estimate qualityadjusted life-years (QALYs) $(40,44,45,47,49)$. Rosenheck et al. (2016) applied a published mapping algorithm to estimate utility weights from Positive and Negative Symptom Scale (PANSS) scores using standard gamble and visual analogue scales $(48,50)$.

The 10 CEAs used eight different measures of health benefit. Three used the Global Assessment of Functioning (GAF), a scoring system for severity of illness in psychiatry $(38,44,46)$. Other psychiatric measures included full vocational recovery $(41)$, the Social Functioning Scale (43) and PANSS negative scale scores (47). One study used a subset of the Wechsler Adult Intelligence Scale-III (WAIS-III) focusing on working memory (42). Another used the generic Quality of Life Scale (48). The studies focusing on participants with BD conducted a CEA using the cost per days free of bipolar episodes (39) and the cost to avoid one relapse or to gain a relapse-free year (49). The heterogeneity in outcome measures used means that it is difficult to determine an overall, comparative, estimate of cost-effectiveness. This is a common issue with CEAs, as there are no agreed threshold levels of cost per disease-specific outcome (51-53).

Included costs-The most common perspective taken within included studies was that of the healthcare provider (7/12) $(39,40,45,47-49)$. Types of costs differed across studies. One study considered costs of schizophrenia-related health care only, excluding assertive community treatment and all other costs. This was the most limited inclusion of costs in the identified studies (45). Other studies captured intervention, inpatient, outpatient, and residential day service costs. Most included primary and community care, medication and social workers (10/12). Less common costs included were: criminal justice services (3/12) 
$(41,42,44)$, patient out of pocket costs $(3 / 12)(38,40,43)$, social security benefits (e.g. sick pay) (42), lost wages (43) and informal care (all 1/12) (43). Three studies discounted future costs. $(38,44,46)$. However, this was not necessary in most studies due to the short time horizons ( $<1$ or 2 years). Two studies appeared to collect certain costs but did not report them. The first described the inclusion of productivity losses; later excluding these because fewer than $5 \%$ of participants were employed at baseline (44). The second detailed that medication data were collected but not costed. It is unlikely that this omission has an important bearing on cost-effectiveness conclusions, as interventions are unlikely to affect medication use within the short study timeframe (47).

Risk of bias-All economic evaluations were conducted using data collected in trials. One trial was non-randomised, increasing the risk of selection bias (45). The remaining evaluations were part of randomised trials, generally regarded as robust evidence. Over half reported that assessors were blinded but blinding of clinicians and participants was not possible due to the intervention types $(38,39,42,44,46,47,49)$. The remaining studies did not report blinding $(40,41,43,45,48)$. While blinding is important in reducing study bias, it is accepted that blinding is more challenging in non-pharmacological trials (54). All studies showed that arms were similar at baseline, with no significant differences that may confound results. Six studies confirmed that they were not powered to detect differences in costeffectiveness (42-44,46-48); the remainder did not report this information. Two studies applied a complete case analysis $(41,46)$, two did not report how they handled missing data $(42,48)$ and 8 imputed missing data using various techniques $(38-40,43-45,47,49)$. Eight studies explicitly adjusted for a variety of baseline demographic data $(38-42,44,47,49)$.

Follow-up ranged from 6-months to 5-years (median 18 months). Only two studies were over 2 years in duration.

\section{Study results}

The key results from included studies are presented in Table 3. It is important to note that these results reflect varying time horizons.

All included studies found empirical clinical improvements in the intervention arm. Six noted that this difference was statistically significant, including 5/6 CBT studies and half of all team-based interventions (2/4) $(38,39,41-43,45,48)$. Barton et al. (2009) also considered a CBT intervention but did not describe whether the change was statistically significant (40). One of the team-based interventions (early interventions for first-episode psychosis) was found to cause no significant change in health (46). Two 'experimental' treatments (art therapy and body psychotherapy) did not have a statistically significant impact on health $(44,47)$. The third (psychoeducation) did not report statistical significance, however, the $95 \%$ CI for the trial analysis did not cross zero for QALYs, indicating a statistically significant result (49). Camacho et al. (2017) reported that the within trial economic analysis demonstrated a net benefit of group psycho-education (vs group peer support) on three health benefit measures (QALYs, relapse avoided and relapse free years). The authors used an economic model to explore the cost effectiveness of group psychotherapy compared to treatment as usual. This also found a net improvement in QALYs for group psychotherapy. 
However, the 95\% confidence intervals crossed zero, suggesting this difference was not statistically significant (49).

Incremental costs were highly uncertain. All but two studies noted that the impact of the intervention on overall costs was not statistically significant $(38,39,41-48)$. The two remaining studies did not report any statistical significance testing (30); one of these did show that the $95 \%$ CI crossed zero, indicating incremental costs were not statistically significant (49). The study by Hastrup et al. (2013) stands out as an outlier, reporting the highest intervention saving of $\$ 35,864$ per patient, but with the longest follow-up period (5 years) (46). Six studies conducted some form of sensitivity analysis on costs including: omitting medication costs, varying discount rates, and assuming therapy groups were run by volunteers $(38,40,44,46-48)$. None of these sensitivity analyses indicated statistically significant differences in incremental costs. Since they focused on costs only, key drivers of cost-effectiveness are unknown.

ICER results across studies are challenging to summarise due to differences in the chosen measure of health benefit. Seven studies reported cost savings due to the intervention $(38,39,41,42,45-47)$, and therefore the intervention was dominant in cost-effectiveness terms (health improving and cost saving). Four studies reported the ICER using QALYs, ranging from dominant to $\$ 87,562$ per QALY. Studies reported the likelihood of cost-effectiveness relative to a specified cost-per-outcome threshold, and this raises one of the key limitations of the studies: recommended thresholds only exist for QALYs $(52,55,56)$. Three studies presented the percentage likelihood of cost-effectiveness conservatively, assuming that the decision maker would not be prepared to pay anything additional for an improvement in health $(38,41,42)$. Given the lack of thresholds for the majority of health benefits, it is left to decision makers to consider how much they would be prepared to pay for specific health gains.

\section{Discussion}

All included studies showed health benefits attributed to the respective intervention, generally to a significant degree, though incremental costs were much more uncertain, as no studies identified a significant impact on costs. The majority of studies therefore concluded that psychological interventions, including CBT, are cost-effective for the treatment of people with schizophrenia. Only two studies were identified for BD with different conclusions regarding cost-effectiveness. A key limitation of the identified literature is that many studies used arbitrary thresholds for cost-effectiveness and no study reported being powered to detect differences in costs so there is some subjectivity around these conclusions.

Heterogeneity across studies makes comparisons challenging, in particular, the use of different measures of health outcome. The variation in outcome measures is likely to be partly due to the lack of a recommended outcome measure. It has been is argued that generic measures of health, such as the EQ-5D, may be insensitive to psychosis symptoms and that a symptom-based measure should be considered (57-59), though others refute this (60-62). One review noted that while there have been many patient-reported outcome measures (PROMs) developed in psychosis, methodological quality is limited and different measures 
focus on different aspects (e.g. treatment satisfaction, quality of life, quality of the therapeutic relationship) (63). This multi-faceted approach to PROMs makes it hard to identify which outcome is the most appropriate. In addition, the choice of outcome measure is likely to be affected by the specific objectives of the intervention, which may focus on one aspect of the illness. There is a continuing debate regarding whether clinical recovery is aligned with patient experience, and thus whether it is truly meaningful to the individual (64).

A further complication is that there are no clear decision-making thresholds for most measures used in studies. Where there is no agreed threshold, the percentage likelihoods of cost-effectiveness produced by studies cannot be meaningfully compared.

The review found limited evidence regarding long-term differences in health and cost outcomes with psychological interventions in this population. Longer-term trials, and modelling studies extrapolating trial data over longer durations, would be useful to resolve this evidence gap.

While the evidence generally supports the use of psychological therapies in this population, decision/policy makers wishing to use the evidence would need to consider whether the results can be generalised to their setting, such as the applicability of standard care in the trial and the age of the population within the trial. They would also have to determine an acceptable willingness to pay for specific health gains. Additionally, there are psychological interventions that have not yet been evaluated for cost-effectiveness, such as mindfulness, for which clinical evidence is heterogeneous and of limited quality (65). No studies were identified that looked at varying medication and introducing psychological treatment concurrently, which would be interesting as these are likely to be used in combination with one another. As more evidence becomes available, this review will need to be updated.

Our findings are similar to previous reviews, suggesting that although the results are predominantly in favour of psychological therapies within this group, there are issues of generalisability, uncertainty and a paucity of long-term data (30-32).

This review is subject to a number of limitations. It was restricted to English language articles and did not include unpublished literature. Including the grey literature and unpublished reports may be more likely to identify studies with inconclusive or negative cost-effectiveness results (66). Additionally, studies have found that economic data are more susceptible to publication bias when compared to clinical data (67). However, a search of the grey literature was outside the scope and resources for this review. Nevertheless, our review did identify published studies with inconclusive results (e.g. demonstrated by the reporting of non-significant cost outcomes) and negative results, which may mitigate the impact of publication bias. Our setting type did not include online interventions; although no studies were screened out because of this. The growth of online therapies in mental health has so far focused on adults with depression and anxiety. However, it is likely that future studies will consider the role of technology in the treatment of severe mental illness meaning that the scope of future reviews will need to be expanded (68). Finally, the review included 
psychological therapies, as existing reviews typically focused on pharmaceuticals. However, it may be useful to view findings for each intervention type side by side.

The review highlights a number of important considerations for future research; longer-term evidence, from randomised controlled trials and/or economic modelling studies, is needed to assess all important differences in health and cost outcomes from psychological interventions for schizophrenia and BD. Future studies should consider the comparability and ease of interpretation of their cost-effectiveness results; decision makers are unlikely to be able to draw firm conclusions from an evidence base comprising such varied measures of health benefit. Generic measures of benefit, such as QALYs, can be easily compared across studies and even disease groups. Furthermore, QALYs have well-defined thresholds against which to base decisions regarding cost-effectiveness. Sensitivity analyses of clinical data, which can identify key drivers of cost-effectiveness, were generally lacking in the included studies. This form of analysis can characterise decision uncertainty and also guide future data collection. Finally, most studies were conducted in the UK and Europe. Research findings from a wider range of geographical settings are needed to ensure that decision makers have evidence that is generalisable to their jurisdiction.

\section{Supplementary Material}

Refer to Web version on PubMed Central for supplementary material.

\section{Acknowledgments}

Financial support

This paper presents independent research funded by the National Institute for Health Research (NIHR) under its Programme Grants for Applied Research programme (grant reference no. RP-PG-0611-20004). The views expressed are those of the author(s) and not necessarily those of the NHS, the NIHR or the Department of Health.

\section{References}

1. Vos T. Global, regional, and national incidence, prevalence, and years lived with disability for 310 diseases and injuries, 1990-2015: a systematic analysis for the Global Burden of Disease Study 2015. Lancet. 2016; 388(388):1545-602.cited 2017 Mar 11 [PubMed: 27733282]

2. Hayes JF, Miles J, Walters K, King M, Osborn DPJ. A systematic review and meta-analysis of premature mortality in bipolar affective disorder. Acta Psychiatr Scand. 2015 Jun; 131(6):41725.cited 2017 Nov 21 [PubMed: 25735195]

3. Brown S, Kim M, Mitchell C, Inskip H. Twenty-five year mortality of a community cohort with schizophrenia. Br J Psychiatry. 2010 Feb 2; 196(02):116-21.cited 2018 Mar 4 [PubMed: 20118455]

4. Lawrence D, Hancock KJ, Kisely S. The gap in life expectancy from preventable physical illness in psychiatric patients in Western Australia: retrospective analysis of population based registers. BMJ. 2013 May 21.346:f2539.cited 2018 Mar 4 [PubMed: 23694688]

5. Saha S, Chant D, McGrath J. A Systematic Review of Mortality in Schizophrenia. Arch Gen Psychiatry. 2007 Oct 1.64(10):1123.cited 2018 Mar 4 [PubMed: 17909124]

6. Leucht S, Burkard T, Henderson J, Maj M, Sartorius N. Physical illness and schizophrenia: a review of the literature. Acta Psychiatr Scand. 2007 Nov; 116(5):317-33.cited 2018 Mar 4 [PubMed: 17919153]

7. Millier, A, Schmidt, U, Angermeyer, MC, Chauhan, D, Murthy, V, Toumi, M. , et al. J Psychiatr Res. Vol. 54. Pergamon: 2014. Jul 1, Humanistic burden in schizophrenia: A literature review; 85- 
93. [Internet] Available from: https://www.sciencedirect.com/science/article/pii/ S0022395614001034 [cited 2018 Mar 3]

8. Wahlbeck K, Westman J, Nordentoft M, Gissler M, Laursen TM. Outcomes of Nordic mental health systems: life expectancy of patients with mental disorders. Br J Psychiatry. 2011 Dec 2; 199(06): 453-8.cited 2018 Mar 4 [PubMed: 21593516]

9. Farrelly, S, Clement, S, Gabbidon, J, Jeffery, D, Dockery, L, Lassman, F. , et al. BMC Psychiatry. Vol. 14. BioMed Central; 2014. Dec 29, Anticipated and experienced discrimination amongst people with schizophrenia, bipolar disorder and major depressive disorder: a cross sectional study; 157[Internet] Available from: http://bmcpsychiatry.biomedcentral.com/articles/ 10.1186/1471-244X-14-157 [cited 2017 Nov 21]

10. Thornicroft G, Brohan E, Rose D, Sartorius N, Leese M, INDIGO Study Group. Global pattern of experienced and anticipated discrimination against people with schizophrenia: a cross-sectional survey. Lancet. 2009 Jan 31; 373(9661):408-15.cited 2017 Nov 21 [PubMed: 19162314]

11. Karidi MV, Vassilopoulou D, Savvidou E, Vitoratou S, Maillis A, Rabavilas A, et al. Bipolar disorder and self-stigma: A comparison with schizophrenia. J Affect Disord. 2015 Sep 15.184:209-15.cited 2017 Nov 21 [PubMed: 26112330]

12. Pattyn E, Verhaeghe M, Sercu C, Bracke P. Medicalizing versus psychologizing mental illness: what are the implications for help seeking and stigma? A general population study. Soc Psychiatry Psychiatr Epidemiol. 2013 Oct 9; 48(10):1637-45.cited 2017 Nov 21 [PubMed: 23474612]

13. Foruzandeh N, Parvin N. Occupational therapy for inpatients with chronic schizophrenia: A pilot randomized controlled trial. Japan J Nurs Sci. 2013 Jun; 10(1):136-41.cited 2017 Nov 21 [PubMed: 23735098]

14. Killackey EJ, Jackson HJ, Gleeson J, Hickie IB, Mcgorry PD. Exciting Career Opportunity Beckons! Early Intervention and Vocational Rehabilitation in First-Episode Psychosis: Employing Cautious Optimism. Aust New Zeal J Psychiatry. 2006 Nov 17; 40(11-12):951-62.cited 2017 Nov 21

15. Szkultecka-Dębek M, Miernik K, Stelmachowski J, Jakovljević M, Jukić V, Aadamsoo K, et al. Schizophrenia causes significant burden to patients' and caregivers' lives. Psychiatr Danub. 2016 Jun; 28(2):104-10.cited 2017 Nov 21 [PubMed: 27287783]

16. Wilens TE, Biederman J, Forkner P, Ditterline J, Morris M, Moore H, et al. Patterns of Comorbidity and Dysfunction in Clinically Referred Preschool and School-Age Children with Bipolar Disorder. J Child Adolesc Psychopharmacol. 2003 Dec; 13(4):495-505.cited 2017 Nov 21 [PubMed: 14977462]

17. Carlborg A, Ferntoft L, Thuresson M, Bodegard J. Population study of disease burden, management,and treatment of bipolar disorder in Sweden: a retrospective observational registry study. Bipolar Disord. 2015 Feb; 17(1):76-85.cited 2017 Nov 21 [PubMed: 25056132]

18. Marwaha S, Durrani A, Singh S. Employment outcomes in people with bipolar disorder: a systematic review. Acta Psychiatr Scand. 2013 Sep; 128(3):179-93.cited 2017 Nov 21 [PubMed: 23379960]

19. Judd LL, Schettler PJ, Solomon DA, Maser JD, Coryell W, Endicott J, et al. Psychosocial disability and work role function compared across the long-term course of bipolar I, bipolar II and unipolar major depressive disorders. J Affect Disord. 2008 May; 108(1-2):49-58.cited 2017 Nov 21 [PubMed: 18006071]

20. Chaiyakunapruk, N, Chong, HY, Teoh, SL, Wu, DB-C, Kotirum, S, Chiou, C-F. Neuropsychiatr Dis Treat. Vol. 12. Dove Press; 2016. Feb 16, Global economic burden of schizophrenia: a systematic review; 357[Internet] Available from: https:/www.dovepress.com/global-economicburden-of-schizophrenia-a-systematic-review-peer-reviewed-article-NDT [cited 2017 Nov 21]

21. McCrone, P; Dhanasiri, S; Patel, A; MArtin, K; Lawton-Smith, S. [cited 2016 Feb 12] Paying the Price: the cost of mental health care in England to 2026. 2008. [Internet] Available from: http:// www.kingsfund.org.uk/sites/files/kf/Paying-the-Price-the-cost-of-mental-health-careEngland-2026-McCrone-Dhanasiri-Patel-Knapp-Lawton-Smith-Kings-Fund-May-2008_0.pdf

22. Kennedy JL, Altar CA, Taylor DL, Degtiar I, Hornberger JC. The social and economic burden of treatment-resistant schizophrenia. Int Clin Psychopharmacol. 2014 Mar; 29(2):63-76.cited 2017 Nov 21 [PubMed: 23995856] 
23. McDonagh, MS, Dana, T, Selph, S, Devine, EB, Cantor, A, Bougatsos, C. , et al. Treatments for Schizophrenia in Adults: A Systematic Review. Agency for Healthcare Research and Quality (US); 2017. [Internet]. Treatments for Schizophrenia in Adults: A Systematic Review [cited 2018 Dec 3]

24. Fountoulakis KN, Vieta E. Treatment of bipolar disorder: a systematic review of available data and clinical perspectives. Int J Neuropsychopharmacol. 2008 Nov 28; 11(07):999-1029.cited 2018 Dec 3 [PubMed: 18752718]

25. Pfammatter, M, Junghan, UM, Brenner, HD. Schizophr Bull. Vol. 32. Oxford University Press; 2006. Oct, Efficacy of psychological therapy in schizophrenia: conclusions from meta-analyses; S64-80. [Internet] [cited 2018 Dec 3]

26. Swartz, HA, Swanson, J. Focus (Am Psychiatr Publ). Vol. 12. NIH Public Access; 2014. Psychotherapy for Bipolar Disorder in Adults: A Review of the Evidence; 251-66. [Internet] [cited 2018 Dec 3]

27. The National Institute for Health and Care Excellence. Quality standard [QS95]. and guidelines | NICE. Bipolar disorder in adultsNICE; Available from: https://www.nice.org.uk/guidance/qs95/ chapter/Quality-statement-4-developmental-Psychological-interventions [cited 2018 Dec 12]

28. The National Institute for Health and Care Excellence. Quality standard[QS80]. Psychosis and schizophrenia in adultsNICE; Available from: https://www.nice.org.uk/guidance/qs80/chapter/ Quality-statement-2-Cognitive-behavioural-therapy [cited 2018 Dec 12]

29. Reilly S, Planner C, Hann M, Reeves D, Nazareth I, Lester H. The Role of Primary Care in Service Provision for People with Severe Mental Illness in the United Kingdom. Baradaran HR. PLoS One. 2012 May 15.7(5):e36468.cited 2018 Dec 4 [PubMed: 22615769]

30. Amos A. Assessing the cost of early intervention in psychosis: A systematic review. Aust New Zeal J Psychiatry. 2012 Aug 13; 46(8):719-34.cited 2017 Nov 21

31. Desmedt M, Vertriest S, Hellings J, Bergs J, Dessers E, Vankrunkelsven P, et al. Economic Impact of Integrated Care Models for Patients with Chronic Diseases: A Systematic Review. Value Heal. 2016 Sep; 19(6):892-902.cited 2017 Nov 21

32. Abdul Pari AA, Simon J, Wolstenholme J, Geddes JR, Goodwin GM. Economic evaluations in bipolar disorder: a systematic review and critical appraisal. Bipolar Disord. 2014 Sep; 16(6):55782.cited 2017 Nov 21 [PubMed: 24917477]

33. Shields, G; Davies, L; Buck, D; Elvidge, J; H, K. [cited 2018 Mar 3] A systematic review of costeffectiveness evaluations of psychological therapies for schizophrenia and bipolar disorder. PROSPERO 2017 CRD42017056579. 2016. [Internet] Available from: http://www.crd.york.ac.uk/ PROSPERO/display_record.php?ID=CRD42017056579

34. Centre for Reviews and Dissemination. [cited 2015 Dec 18] NHS Economic Evaluation Database (NHS EED) Handbook. 2007. [Internet] Available from: http://www.york.ac.uk/inst//crd/pdf/ nhseed-handbook2007.pdf

35. Husereau, D, Drummond, M, Petrou, S, Carswell, C, Moher, D, Greenberg, D. , et al. BMJ. Vol. 346. British Medical Journal Publishing Group; 2013. Mar 25, Consolidated Health Economic Evaluation Reporting Standards (CHEERS) statement. f1049 [Internet] [cited 2018 Dec 4]

36. OECD. [cited 2018 Aug 7] Prices - Inflation (CPI) - OECD Data. 2018. [Internet]. Available from: https://data.oecd.org/price/inflation-cpi.htm

37. OECD Purchasing Power Parities (PPPs) Data. [cited 2018 Aug 7] 2018. [Internet]. Available from: https://stats.oecd.org/Index.aspx?DataSetCode=CPL\#

38. Haddock G, Barrowclough C, Tarrier N, Moring J, O’Brien R, Schofield N, et al. Cognitivebehavioural therapy and motivational intervention for schizophrenia and substance misuse. 18month outcomes of a randomised controlled trial. Br J Psychiatry. 2003 Nov.183:418-26.cited 2017 Nov 21 [PubMed: 14594917]

39. Lam, DH, McCrone, P, Wright, K, Kerr, N. Br J Psychiatry. Vol. 186. The Royal College of Psychiatrists; 2005. Jun 1, Cost-effectiveness of relapse-prevention cognitive therapy for bipolar disorder: 30-month study; 500-6. [Internet] [cited 2017 Nov 21]

40. Barton GR, Hodgekins J, Mugford M, Jones PB, Croudace T, Fowler D. Cognitive behaviour therapy for improving social recovery in psychosis: Cost-effectiveness analysis. Schizophr Res. 2009 Jul; 112(1-3):158-63.cited 2017 Nov 21 [PubMed: 19403270] 
41. McCrone, P, Craig, TKJ, Power, P, Garety, PA. Br J Psychiatry. Vol. 196. The Royal College of Psychiatrists; 2010. May 1, Cost-effectiveness of an early intervention service for people with psychosis; 377-82. [Internet] [cited 2017 Nov 21]

42. Patel A, Knapp M, Romeo R, Reeder C, Matthiasson P, Everitt B, et al. Cognitive remediation therapy in schizophrenia: Cost-effectiveness analysis. Schizophr Res. 2010 Jul; 120(1):21724.cited 2017 Nov 21 [PubMed: 20056391]

43. van der Gaag, M, Stant, AD, Wolters, KJK, Buskens, E, Wiersma, D. Br J Psychiatry. Vol. 198. The Royal College of Psychiatrists; 2011. Jan 1, Cognitive-behavioural therapy for persistent and recurrent psychosis in people with schizophrenia-spectrum disorder: cost-effectiveness analysis; 59-65. [Internet] [cited 2017 Nov 21]

44. Crawford M, Killaspy H, Barnes T, Barrett B, Byford S, Clayton K, et al. Group art therapy as an adjunctive treatment for people with schizophrenia: a randomised controlled trial (MATISSE). Health Technol Assess (Rockv). 2012 Feb; 16(8):iii-iv.cited 2017 Nov 21

45. Karow A, Reimer J, König HH, Heider D, Bock T, Huber C, et al. Cost-Effectiveness of 12-Month Therapeutic Assertive Community Treatment as Part of Integrated Care Versus Standard Care in Patients With Schizophrenia Treated With Quetiapine Immediate Release (ACCESS Trial). J Clin Psychiatry. 2012 Mar 15; 73(03):e402-8.cited 2017 Nov 21 [PubMed: 22490266]

46. Hastrup LH, Kronborg C, Bertelsen M, Jeppesen P, Jorgensen P, Petersen L, et al. Costeffectiveness of early intervention in first-episode psychosis: economic evaluation of a randomised controlled trial (the OPUS study). Br J Psychiatry. 2013 Jan 1; 202(1):35-41.cited 2017 Nov 21 [PubMed: 23174515]

47. Priebe S, Savill M, Wykes T, Bentall R, Lauber C, Reininghaus U, et al. Clinical effectiveness and cost-effectiveness of body psychotherapy in the treatment of negative symptoms of schizophrenia: a multicentre randomised controlled trial. Health Technol Assess (Rockv). 2016 Feb; 20(11):1100.cited 2017 Nov 21

48. Rosenheck R, Leslie D, Sint K, Lin H, Robinson DG, Schooler NR, et al. Cost-Effectiveness of Comprehensive, Integrated Care for First Episode Psychosis in the NIMH RAISE Early Treatment Program. Schizophr Bull. 2016 Jul; 42(4):896-906.cited 2017 Nov 21 [PubMed: 26834024]

49. Camacho EM, Ntais D, Jones S, Riste L, Morriss R, Lobban F, et al. Cost-effectiveness of structured group psychoeducation versus unstructured group support for bipolar disorder: Results from a multi-centre pragmatic randomised controlled trial. J Affect Disord. 2017; 211:27-36. [PubMed: 28086146]

50. Lenert L, Sturley AP, Rapaport MH, Chavez S, Mohr PE, Rupnow M. Public preferences for health states with schizophrenia and a mapping function to estimate utilities from positive and negative symptom scale scores. Schizophr Res. 2004 Nov 1; 71(1):155-65.cited 2018 Mar 3 [PubMed: 15374583]

51. Shiroiwa, T, Sung, Y-K, Fukuda, T, Lang, H-C, Bae, S-C, Tsutani, K. Health Econ. Vol. 19. John Wiley \& Sons, Ltd; 2010. Apr 1, International survey on willingness-to-pay (WTP) for one additional QALY gained: what is the threshold of cost effectiveness?; 422-37. [Internet] [cited 2018 Mar 3]

52. Neumann, PJ, Cohen, JT, Weinstein, MC. N Engl J Med. Vol. 371. Massachusetts Medical Society; 2014. Aug 28, Updating Cost-Effectiveness - The Curious Resilience of the \$50,000-per-QALY Threshold; 796-7. [Internet] [cited 2018 Mar 3]

53. Claxton K, Martin S, Soares M, Rice N, Spackman E, Hinde S, et al. Methods for the estimation of the National Institute for Health and Care Excellence cost-effectiveness threshold. Health Technol Assess. 2015 Feb; 19(14):1-503.cited 2015 Nov 17

54. Boutron I, Tubach F, Giraudeau B, Ravaud P. Blinding was judged more difficult to achieve and maintain in nonpharmacologic than pharmacologic trials. J Clin Epidemiol. 2004 Jun; 57(6):54350.cited 2017 Sep 14 [PubMed: 15246122]

55. National Institute for Health and Care Excellence. Guide to the methods of technology appraisal 2013. NICE; 2013. [Internet]. Available from: https://www.nice.org.uk/process/pmg9/chapter/ foreword [cited 2018 Aug 10]

56. Nimdet K, Chaiyakunapruk N, Vichansavakul K, Ngorsuraches S. A systematic review of studies eliciting willingness-to-pay per quality-adjusted life year: does it justify CE threshold? PLoS One. 2015 Jan.10(4):e0122760.cited 2015 Nov 9 [PubMed: 25855971] 
57. Connell, J, O'Cathain, A, Brazier, J. Soc Sci Med. Vol. 120. Pergamon: 2014. Nov 1, Measuring quality of life in mental health: Are we asking the right questions?; 12-20. [Internet]. Available from: https://www.sciencedirect.com/science/article/pii/S0277953614005437 [cited 2018 Mar 3]

58. Mulhern B, Mukuria C, Barkham M, Knapp M, Byford S, Soeteman D, et al. Using generic preference-based measures in mental health: psychometric validity of the EQ-5D and SF-6D. Br J Psychiatry. 2014 Sep 2; 205(03):236-43.cited 2018 Mar 3 [PubMed: 24855127]

59. Brazier J. Is the EQ-5D fit for purpose in mental health? Br J Psychiatry. 2010 Nov 1; 197(5):3489.cited 2017 Mar 16 [PubMed: 21037210]

60. S, M, A, E, V, JA, L., N, H, D, M, P. , et al. Journal of Affective Disorders. Vol. 147. Netherlands: Elsevier (P.O. Box2, Amsterdam 1000 AE Netherlands); 2013. Impact of psychiatric disorders and chronic physical conditions on health-related quality of life: Singapore Mental Health Study; 32530. [Internet]. Available from:NS -

61. Konig, H-H, Born, A, Gunther, O, Matschinger, H, Heinrich, S, Riedel-Heller, SG., et al. Health Qual Life Outcomes. Vol. 8. England: 2010. Validity and responsiveness of the EQ-5D in assessing and valuing health status in patients with anxiety disorders; 47[Internet]. (101153626 PG-47) Available from: NS -

62. Hayhurst, H, Palmer, S, Abbott, R, Johnson, T, Scott, J. Qual Life Res. Vol. 15. Kluwer Academic Publishers; 2006. Oct 30, Measuring health-related quality of life in bipolar disorder: Relationship of the EuroQol (EQ-5D) to condition-specific measures; 1271-80. [Internet] [cited 2018 Mar 3]

63. Reininghaus, U, Priebe, S. Br J Psychiatry. Vol. 201. Cambridge University Press; 2012. Oct 2, Measuring patient-reported outcomes in psychosis: conceptual and methodological review; 262-7. [Internet]. Available from:https://www.cambridge.org/core/product/identifier/ S0007125000272486/type/journal_article [cited 2018 Mar 3]

64. Macpherson, R, Pesola, F, Leamy, M, Bird, V, Le Boutillier, C, Williams, J., et al. Schizophr Res. Vol. 175. Elsevier; 2016. Aug 1, The relationship between clinical and recovery dimensions of outcome in mental health; 142-7. [Internet] [cited 2018 Mar 3]

65. Langer AI, Schmidt C, Mayol R, Diaz M, Lecaros J, Krogh E, et al. The effect of a mindfulnessbased intervention in cognitive functions and psychological well-being applied as an early intervention in schizophrenia and high-risk mental state in a Chilean sample: study protocol for a randomized controlled trial. Trials. 2017; 18(1):233. [PubMed: 28545578]

66. Bell CM, Urbach DR, Ray JG, Bayoumi A, Rosen AB, Greenberg D, et al. Bias in published cost effectiveness studies: systematic review. BMJ. 2006; 332(7543)

67. Thorn JC, Noble SM, Hollingworth W. Timely and Complete Publication of Economic Evaluations Alongside Randomized Controlled Trials. Pharmacoeconomics. 2013 Jan 28; 31(1):77-85.cited 2018 Dec 12 [PubMed: 23329594]

68. Lal, S, Adair, CE. Psychiatr Serv. Vol. 65. American Psychiatric Association; Arlington, VA: 2014. Jan 1, E-Mental Health: A Rapid Review of the Literature; 24-32. [Internet] [cited 2018 Dec 4] 


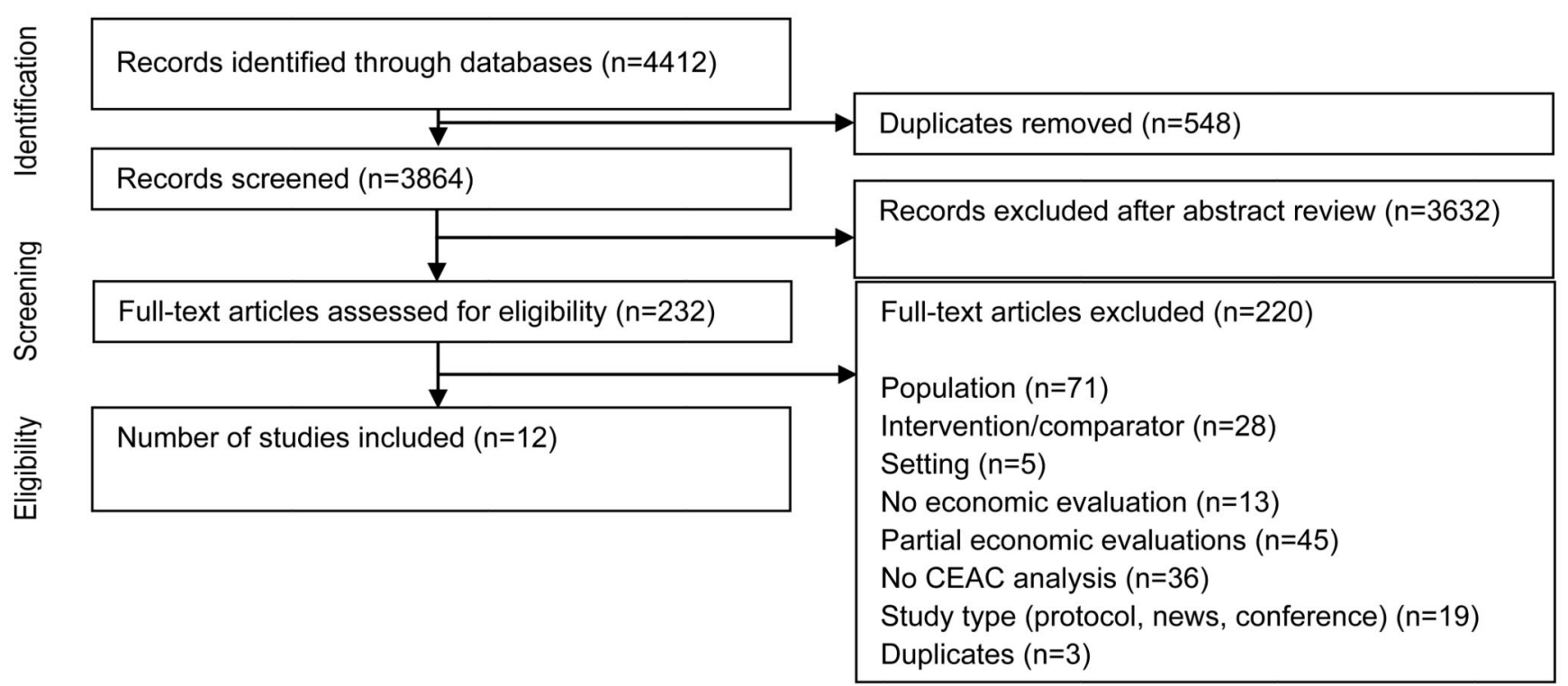

Figure 1. Identification of studies 
Table 1

Inclusion criteria for systematic review of psychological interventions for schizophrenia and bipolar disorder

\begin{tabular}{|l|l|}
\hline Criterion & Requirement for Inclusion \\
\hline Population & $\begin{array}{l}\text { Adults with schizophrenia or bipolar disorder. Studies that included individuals with dual diagnosis and/or co-morbidity } \\
\text { were eligible for inclusion. }\end{array}$ \\
\hline Intervention & $\begin{array}{l}\text { Psychological interventions, which include 'psychological therapy', IAPT (Improving Access to Psychological } \\
\text { Therapies), integrated care, collaborative care, talking therapies, psychological well-being practitioners, and/or liaison } \\
\text { workers. }\end{array}$ \\
\hline Comparator & Comparison with routine practice or no intervention, or with any of the above interventions. \\
\hline Outcomes & $\begin{array}{l}\text { Full economic evaluation relating costs and outcomes in an incremental cost-effectiveness ratio (ICER), or some } \\
\text { measure of net benefit that incorporates health outcomes. Studies had to include a 'cost-effectiveness acceptability } \\
\text { curve' (CEAC) or explicitly report probabilities of being cost-effective to allow for an assessment of uncertainty. }\end{array}$ \\
\hline $\begin{array}{l}\text { Setting and study } \\
\text { type }\end{array}$ & $\begin{array}{l}\text { Studies in a community, primary or outpatient setting. } \\
\text { Studies that include a full economic evaluation comparing both costs and outcomes. } \\
\text { Any study types/designs except case reports. }\end{array}$ \\
\hline Other & Journal articles published in English language between January 2000 and November 2018. \\
\hline
\end{tabular}




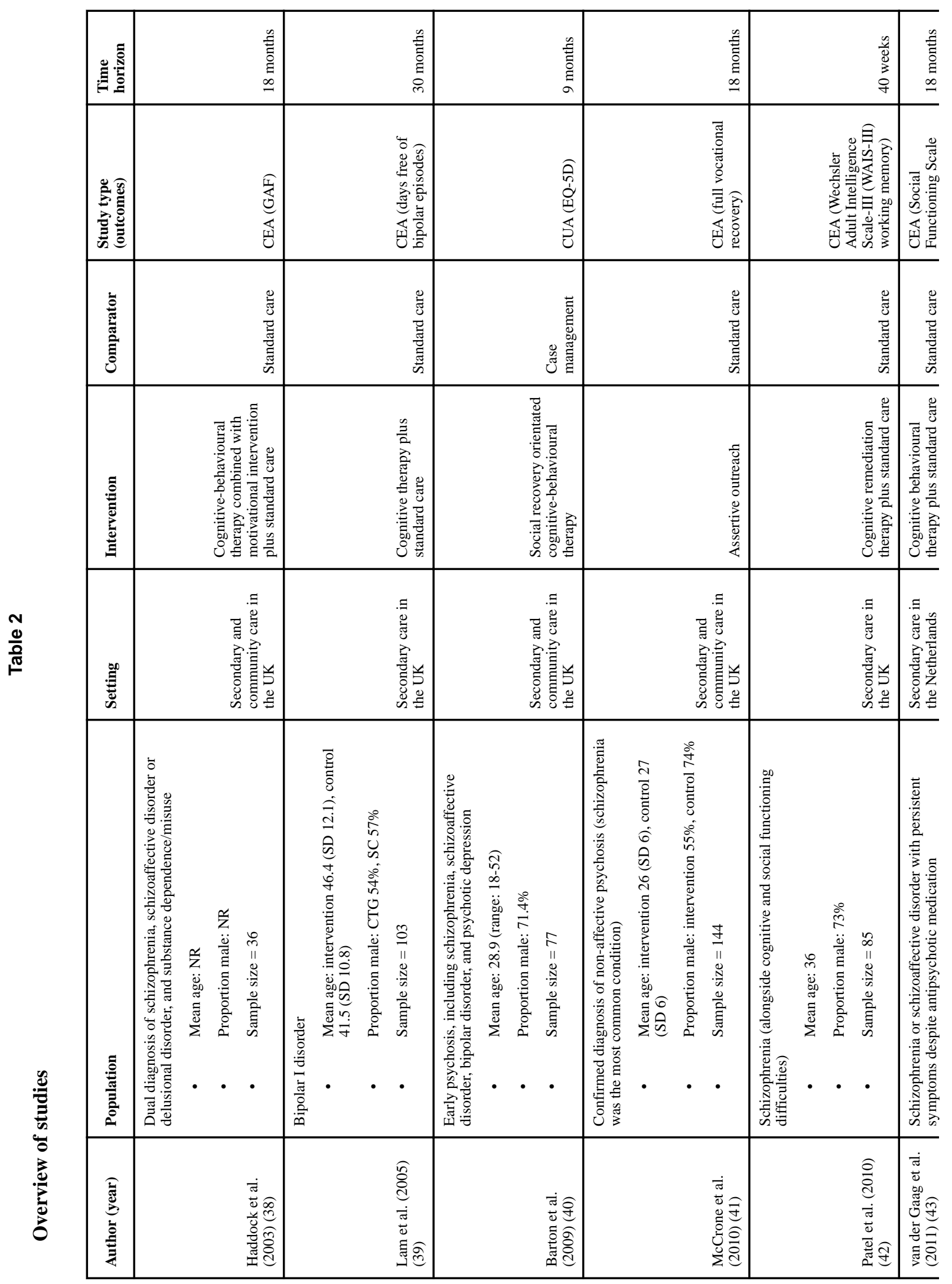

Int J Technol Assess Health Care. Author manuscript; available in PMC 2019 August 23. 


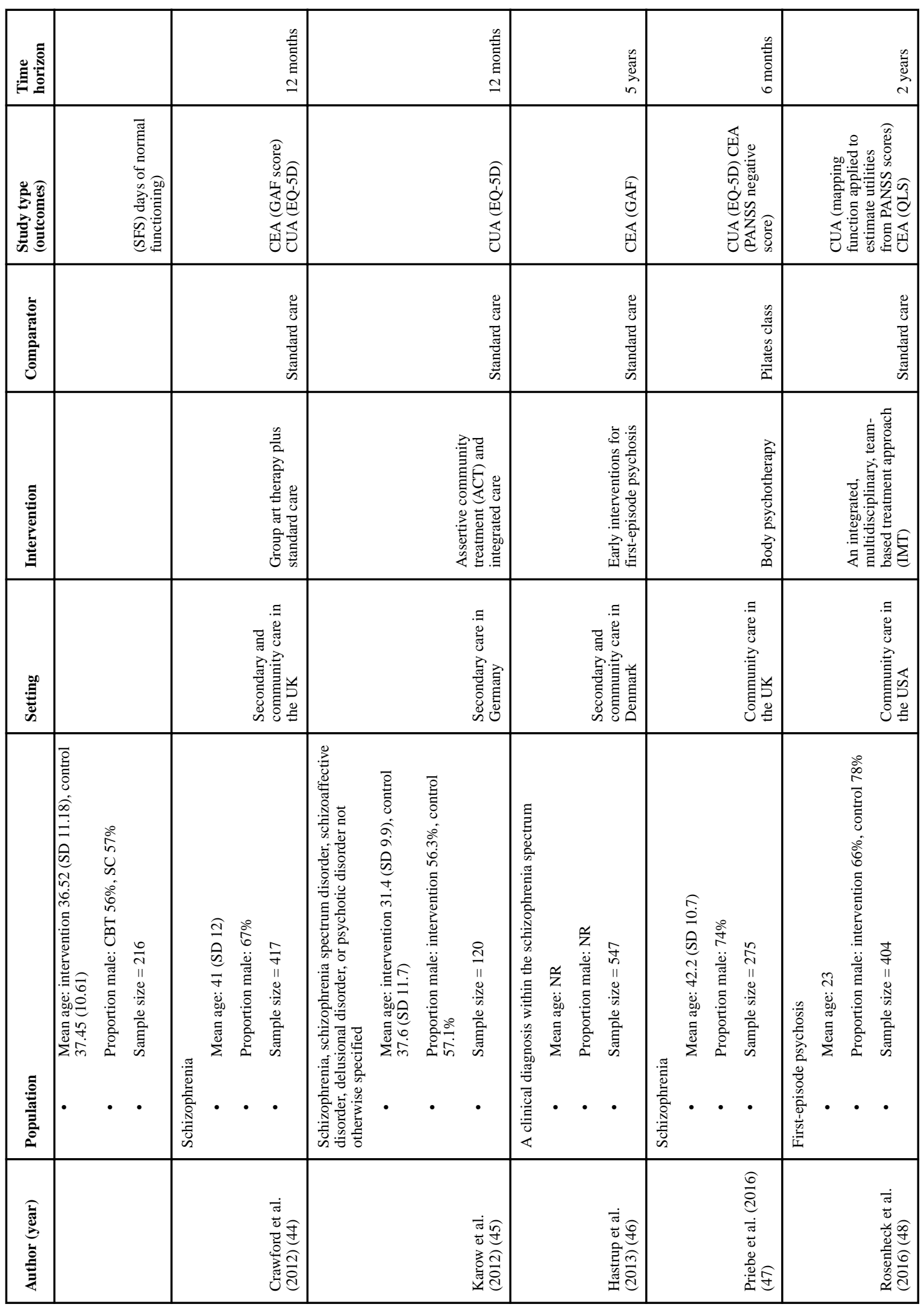




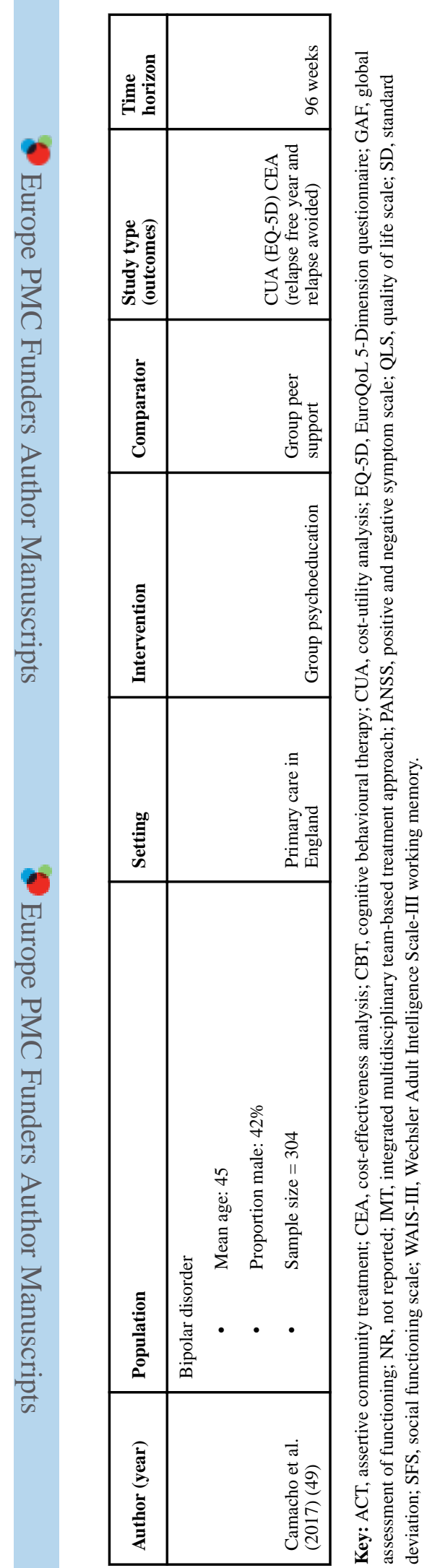

Int J Technol Assess Health Care. Author manuscript; available in PMC 2019 August 23. 


\begin{tabular}{|c|c|c|c|c|c|c|c|c|c|c|c|c|c|}
\hline & 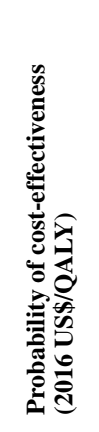 & 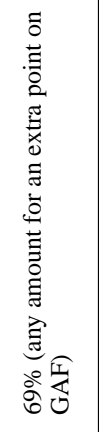 & 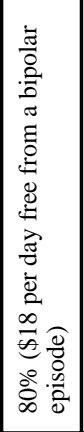 & 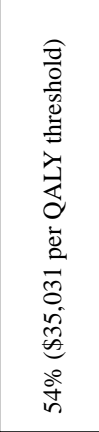 & 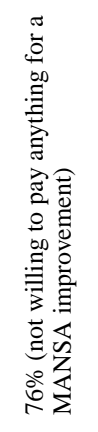 & 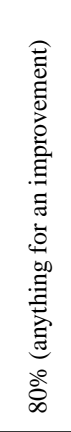 & 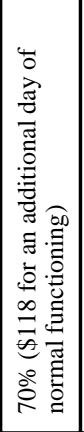 & 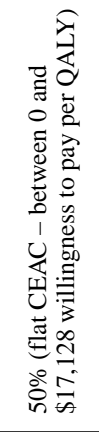 & 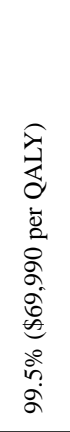 & 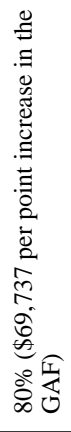 & 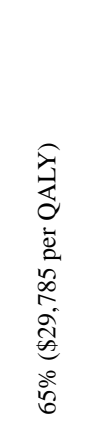 & 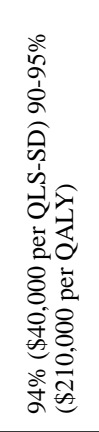 & 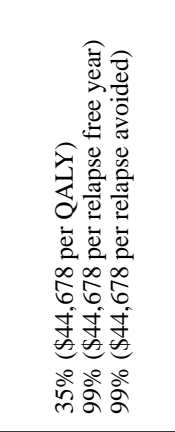 \\
\hline & 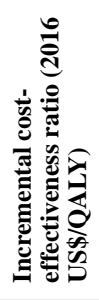 & 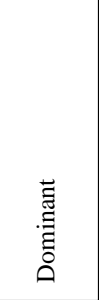 & 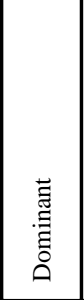 & 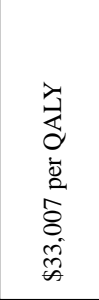 & $\begin{array}{l}\text { 言 } \\
\text { 訔 } \\
\text { 号 }\end{array}$ & $\begin{array}{l}\text { 䓌 } \\
\text { 总 } \\
\text { 号 }\end{array}$ & 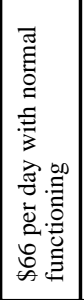 & 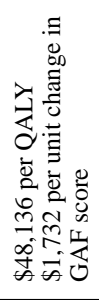 & 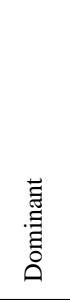 & $\begin{array}{l}\text { 䓂 } \\
\text { 音 } \\
\text { ه }\end{array}$ & $\begin{array}{l}\text { 节 } \\
\text { 音 } \\
\text { ه }\end{array}$ & 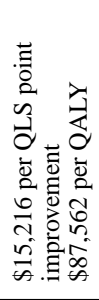 & 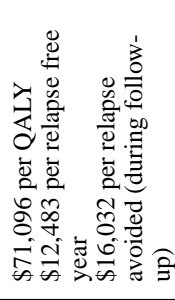 \\
\hline & 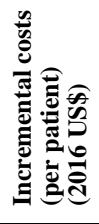 & $\begin{array}{l}\tilde{w} \\
\text { f } \\
\tilde{w} \\
\hat{i}\end{array}$ & 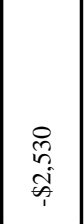 & $\underset{\vec{A}}{\vec{A}}$ & $\begin{array}{l}\text { ఫे } \\
\text { f. } \\
\text { în }\end{array}$ & 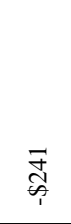 & $\begin{array}{l}\tilde{E} \\
\dot{5} \\
\dot{x}\end{array}$ & $\begin{array}{l}\hat{N} \\
\hat{s} \\
\hat{i} \\
\hat{w}\end{array}$ & $\begin{array}{l}\tilde{W} \\
\text { w. } \\
\text { ô. }\end{array}$ & $\begin{array}{l}\mathbf{0} \\
\infty \\
\infty \\
0 \\
\hat{n}\end{array}$ & $\hat{\hat{n}}$ & \begin{tabular}{l}
\multirow{2}{0}{} \\
$\infty$ \\
$\infty$ \\
$\infty$
\end{tabular} & $\begin{array}{l}\hat{\sigma} \\
\frac{1}{\infty}\end{array}$ \\
\hline & 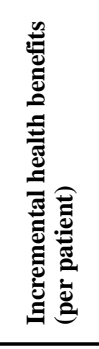 & 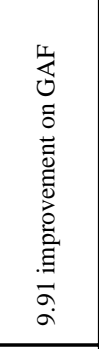 & 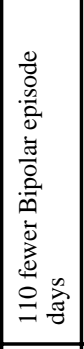 & 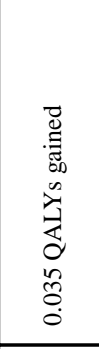 & 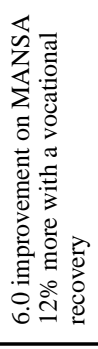 & 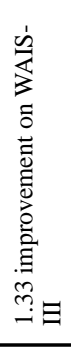 & 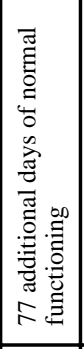 & 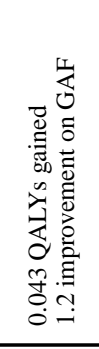 & 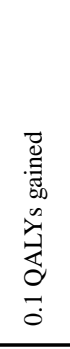 & 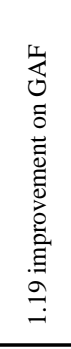 & 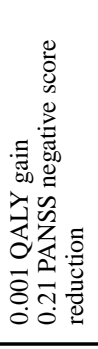 & 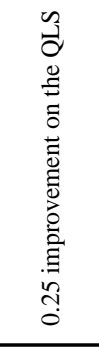 & 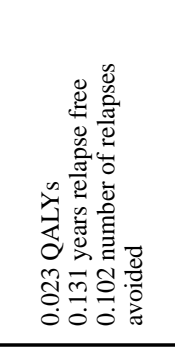 \\
\hline \multirow{2}{*}{ 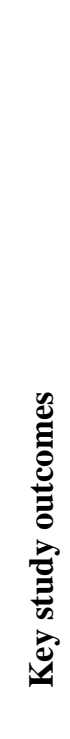 } & 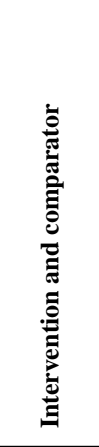 & 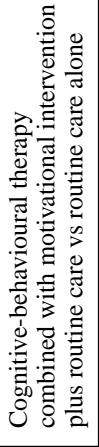 & 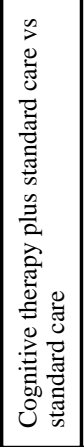 & 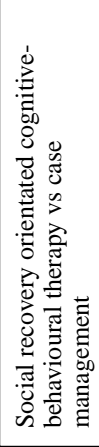 & 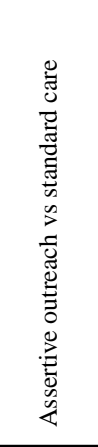 & 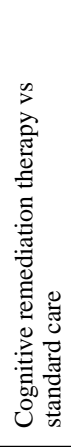 & 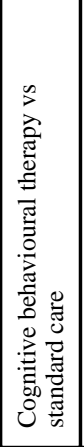 & 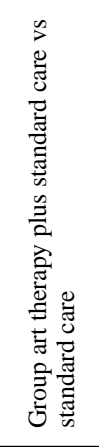 & 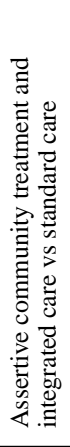 & 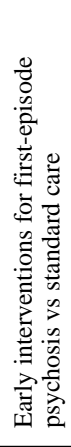 & 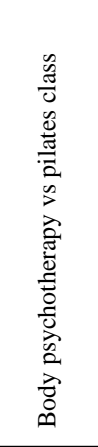 & 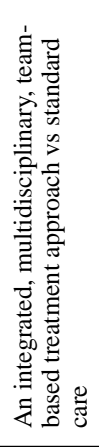 & 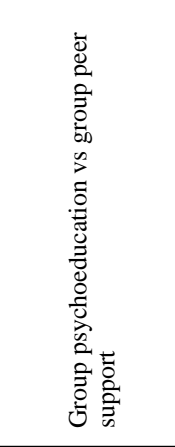 \\
\hline & 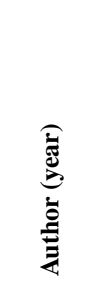 & 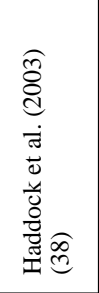 & 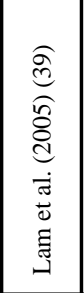 & 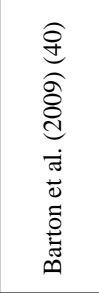 & 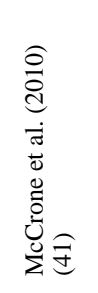 & 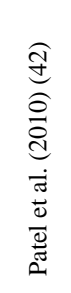 & 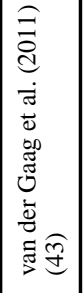 & 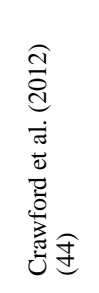 & 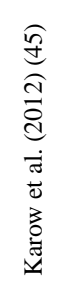 & 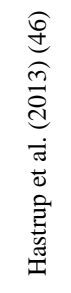 & 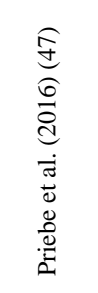 & 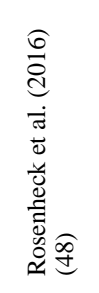 & 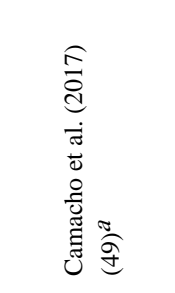 \\
\hline
\end{tabular}


